KANSAS JOURNAL of MEDICINE

\section{Cut Cortical Screw Purchase in Diaphyseal Bone: A Biomedical Study}

Alexander C. Wendling, M.D. ${ }^{1}$, Joel White, BSME, MSBME², Benjamin J. Cooper, M.D. ${ }^{1}$, Chad M. Corrigan, M.D. ${ }^{1,3}$, Bradley R. Dart, M.D. ${ }^{1,3}$

${ }^{1}$ University of Kansas School of Medicine-Wichita, Wichita, KS Department of Orthopaedics ${ }^{2}$ Wichita State University, Wichita, KS

National Institute for Aviation Research, Emerging Technologies and Composites Lab

${ }^{3}$ Advanced Orthopaedic Associates, PA, Wichita, KS Received Nov. 10, 2021; Accepted for publication Nov. 29, 2021; Published online Feb. 9, 2022 https: doi.org 10.17161 kim.vol15.16115

\section{ABSTRACT}

Introduction. During fracture osteosynthesis, traumatologists may remove screws which are too long, cut the excess length from the screw tip, then reinsert the cut screw (CS) to minimize implant waste. The purpose of this study was to determine if this practice influences screw purchase.

Methods. Using an axial-torsion load device, the maximal insertion torque (MIT) required to insert $3.5 \mathrm{~mm}$ stainless steel cortical screws into normal and osteoporotic bone models was measured. MIT was determined in three different test conditions: (1) long screw (LS) insertion; (2) LS insertion, removal, and insertion of a normal-length screw (NS); and, (3) LS insertion, removal, cutting excess length from the screw tip, and reinserting the $\mathrm{CS}$.

Results. In the normal bone model, mean $( \pm$ SD) MIT of LS insertion was $546 \pm 6$ Newton-centimeters $(\mathrm{N}-\mathrm{cm})$ compared to $496 \pm 61$ $\mathrm{N}$-cm for NS reinsertion and $465 \pm 69 \mathrm{~N}$-cm for CS reinsertion. In the osteoporotic bone model, MIT of LS insertion was $110 \pm 11 \mathrm{~N}-\mathrm{cm}$, whereas the values for NS and CS reinsertions were $98 \pm 9 \mathrm{~N}-\mathrm{cm}$ and $101 \pm 12 \mathrm{~N}$-cm, respectively. There was no significant difference in MIT between CS and NS reinsertions in the osteoporotic bone analog.

Conclusions. Cutting excess length from a $3.5 \mathrm{~mm}$ stainless steel cortical screw did not decrease its purchase regardless of bone density. During osteosynthesis, orthopaedists may remove screws which are too long, cut the screw tip, and reinsert the shortened screw as a costsaving measure without compromising fracture fixation.

\section{Kans J Med 2022;15:59-62 \\ INTRODUCTION}

Fracture fixation using plate osteosynthesis is a well-established treatment employing basic principles of biomechanics such as compression and torque. A successful fracture reconstruction depends largely upon the orthopaedist's ability to achieve adequate plate compression by maximizing torque applied to a screw. Many factors affecting screw purchase, including patient characteristics, such as bone density, and mechanical factors, such as screw and plate design features, are not within the surgeon's control. However, the surgical technique used to apply plate and screws to the fractured bone, including possible modification of the screw tip, is determined by the operating orthopaedist.

When cortical screws used during osteosynthesis are too long, they may protrude from the far cortex of bone, potentially causing pain and injury to adjacent soft tissue structures. In this setting, a shorter screw is warranted. How this is accomplished varies as some surgeons discard the long screw (LS) and replace it with a new screw (NS) of appropriate length, whereas others choose to remove the long screw, cut it to the required length, and reinsert the cut screw (CS). In the latter scenario, the orthopaedist saves the cost associated with wasting the LS, which may not be reused in another patient. One hospital system found that $3.5 \%$ of all trauma implant costs were due to wasted materials, adding an average of $\$ 83$ to the cost of each case. Incorrectly measured screw lengths were one of the most common reasons for wasted materials, the cumulative cost of which may be significant for a health care system., ${ }^{1,2}$

While other biomechanical studies have assessed the effect of insertion technique, ${ }^{3}$ insertion angle, ${ }^{4}$ and screw pitch $^{5,6}$ on screw purchase, the influence of reinserting a CS is unknown. The purpose of this study was to investigate whether removing an implanted screw, cutting excess length from the screw tip, and reinserting the implant has an effect on screw purchase as determined by the maximal insertion torque (MIT). As deformation caused by cutting a screw alters the distal thread, it was hypothesized that reinserting a CS would remove additional bone, decrease the contact surface area of the screw-bone interface, and decrease screw purchase. This hypothesis was tested by comparing the MIT required to reinsert CS and NS in synthetic bone models.

\section{METHODS}

Experimental Design. Stainless steel screws designed for fracture fixation were inserted into surrogate bone materials approximating normal and osteoporotic femoral diaphyseal bone to determine MIT in three different test conditions (Figure 1). In Condition A, a LS was introduced into each predrilled and untapped hole in the model specimen, MIT was measured, and the LS was removed. In Condition B, a LS was inserted and removed and then a screw of appropriate length, so-called "normal screw" (NS), was inserted, and MIT was measured. In Condition C, a LS was placed into a predrilled and untapped hole and then removed. The LS was then shortened by cutting the screw tip and the resulting cut screw (CS) was reinserted and MIT was remeasured. The values obtained for the three test conditions were statistically analyzed for both bone models.

Test Materials. The two bone analog models intended to simulate normal and osteoporotic bone in this study were like those used in previous biomechanical experiments. ${ }^{78} \mathrm{~A}$ fourth generation Sawbones ${ }^{\oplus}$ (Pacific Research Laboratories, Vashon Island, WA) model with an outer diameter of $30 \mathrm{~mm}$, wall thickness of $7 \mathrm{~mm}$, and an internal fill of 20 \# density foam was used to mimic the normal bone of a mid-shaft femur. The common cylindrical shape of the specimen improved test repeatability as compared to testing with an anatomic model of varying geometry. To simulate osteoporotic bone, a custom Sawbones ${ }^{\varpi}$ foam laminate of $16 \mathrm{~mm}$, thick 10 \# solid foam laminated on both sides with $5.5 \mathrm{~mm} 30$ \# solid foam was used. Each test block had a finished size $120 \mathrm{~mm}$ wide, $170 \mathrm{~mm}$ long, and $27 \mathrm{~mm}$ thick. 


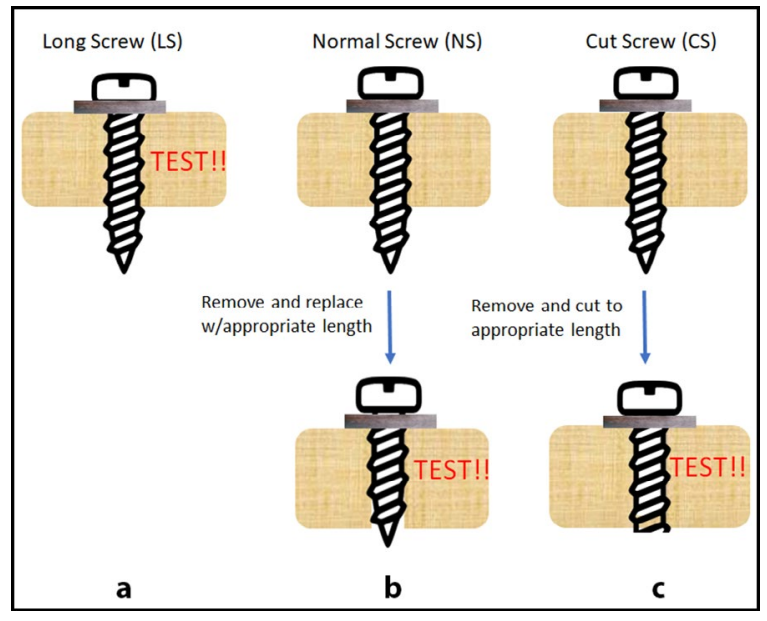

Figure 1. Testing algorithm. a) In Condition A, LS is inserted and test is done to determine MIT. b) In Condition B, LS is inserted, removed, NS is inserted, and MIT is determined. c) In Condition C, LS is inserted, removed, and screw tip is cut to shorten the screw. The resulting CS is reinserted and MIT is determined.

The stainless-steel cortical screws were $3.5 \mathrm{~mm}$ diameter screws manufactured by Stryker ${ }^{\varpi}$ (Mahwah, NJ). The LS measured $40 \mathrm{~mm}$, CS $34 \mathrm{~mm}$, and NS $34 \mathrm{~mm}$. Images of a cut stainless steel screw are shown in Figure 2.

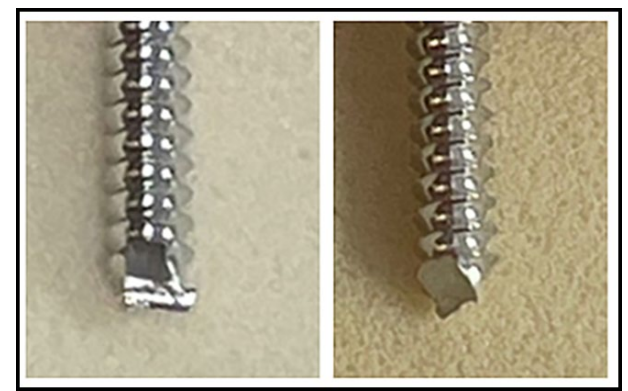

Figure 2. Two views of a stainless-steel cut screw showing mechanical deformation of the screw tip.

Maximal Insertion Torque Testing. Insertional torque was measured continuously on a Bose (Framingham, MA) ElectroForce 3220 Axial-Torsion load frame (Figure 3). An axial preload of $10 \mathrm{~N}$ was applied and held constant for the duration of the screw insertion test. The test was driven at a rotational rate of five revolutions per minute. The time, axial load, axial displacement, rotation angle, and torque were recorded at a data acquisition rate of $10 \mathrm{~Hz}$. The test was performed until failure of the bone-screw interface, screw head stripping, screw head fracture, or a machine torque limit was reached.
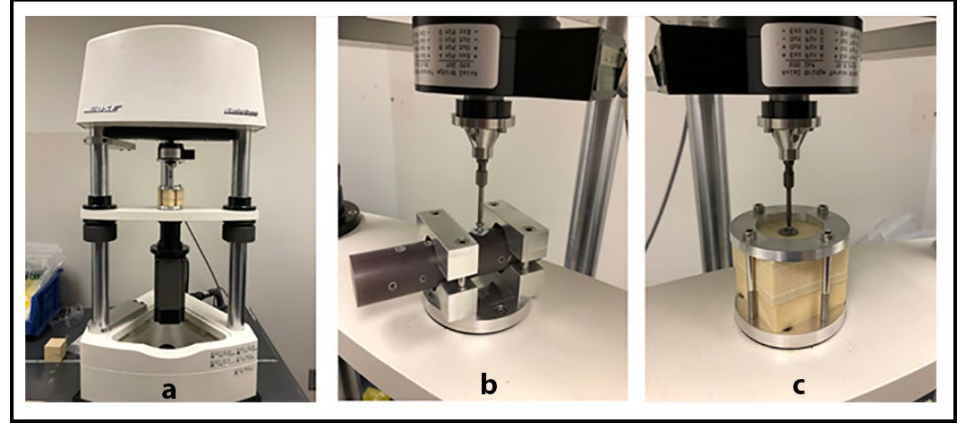

Figure 3. Maximal insertion torque (MIT) testing. a) Screw MIT testing setup; b) Screw insertion into normal cortical bone model; c) Screw insertion into osteoporotic bone model.

\section{KANSAS JOURNAL of MEDICINE}

CUT CORTICAL SCREW PURCHASE

continued.

The torque measuring load frame limit of $550 \mathrm{~N}-\mathrm{cm}$ is well above the torque applied to screws during osteosynthesis. If the screw MIT was greater than $300 \mathrm{~N}-\mathrm{cm}$, the screw was considered not stripped under clinical conditions. ${ }^{7,8,10,11}$

To prepare the bone models for testing, $2.5 \mathrm{~mm}$ diameter holes were drilled perpendicular to the longitudinal axis of the test cylinder. A hole spacing of $12.5 \mathrm{~mm}$ was used to give a five times the diameter spacing between holes as specified by the American Society for Testing and Materials (ASTM). ${ }^{12,13}$ The intent was to insert all screws perpendicular to the long axis of the test cylinder, penetrating both near and far sides of the specimen. A matched washer was used with each screw to simulate a standard bone fracture plate. Screws were started by hand and inserted until the screw head was approximately $4 \mathrm{~mm}$ from contacting the washer.

In the first series of tests using the normal cortical bone model, five replicates of LS, NS, and CS were tested to see if differences in MIT could be found. In the second series using the osteoporotic bone model, seven replicates were tested. Tested screws were removed by hand and each screw was examined for damage. The number of screws tested in each group of the study met or exceeded the number of screws tested in the published literature on MIT.7,8

Statistical Analysis. Statistical analysis of the results was performed by one-way ANOVA test with the Least Significant Difference formula for post hoc multiple comparisons (IBM ${ }^{\oplus}$ SPSS v23, Chicago, IL). Seven independent tests per test condition were summarized for analysis. A p value of less than 0.05 was considered as significant difference. Data were expressed as mean \pm standard deviation (SD) of the mean.

\section{RESULTS}

Normal Bone Analog. The mean \pm SD MIT of initial LS insertion was $546 \pm 6 \mathrm{~N}$-cm and the MIT values for NS and CS reinsertions were $496 \pm 61 \mathrm{~N}-\mathrm{cm}$ and $465 \pm 69 \mathrm{~N}$-cm, respectively (Table 1). The mean value for each test condition in the normal cortical bone model was significantly above the MIT clinically relevant threshold of $300 \mathrm{~N}-\mathrm{cm}$ (p 0.05 ). For the cortical bone surrogate, $70 \%$ of the screw heads broke prior to reaching the MIT machine limit of $550 \mathrm{~N}-\mathrm{cm}$.

Osteoporotic Bone Analog. The MIT of initial LS insertion was $110 \pm 11 \mathrm{~N}-\mathrm{cm}$ and the MIT values for NS and CS reinsertions were $98 \pm 9 \mathrm{~N}-\mathrm{cm}$ and $101 \pm 12 \mathrm{~N}-\mathrm{cm}$, respectively (Table 1). There was no significant difference in MIT between CS and NS in osteoporotic bone.

Table 1. Maximal insertion torque (MIT).

\begin{tabular}{|c|c|c|c|}
\hline Test condition & Screw type & $\begin{array}{c}\text { Normal bone } \\
\text { model }^{*}\end{array}$ & $\begin{array}{c}\text { Osteoporotic } \\
\text { model }^{*}\end{array}$ \\
\hline A & Long screw (LS) & $546 \pm 6$ & $111 \pm 11$ \\
\hline B & Normal screw (NS) & $496 \pm 61$ & $98 \pm 9$ \\
\hline C & Cut screw (CS) & $465 \pm 69$ & $101 \pm 12$ \\
\hline
\end{tabular}

* Tabulated values are mean \pm standard deviation in $\mathrm{N}-\mathrm{cm}$. 
KANSAS JOURNAL of MEDICINE CUT CORTICAL SCREW PURCHASE continued.

Within osteoporotic bone, insertional torque recorded $180^{\circ}$ prior to MIT and $180^{\circ}$ after MIT were compared in CS and NS screws (Figure 4). At each measurement in the $360^{\circ}$ arc, there were no significant differences in torque $(\mathrm{p}<0.05)$.

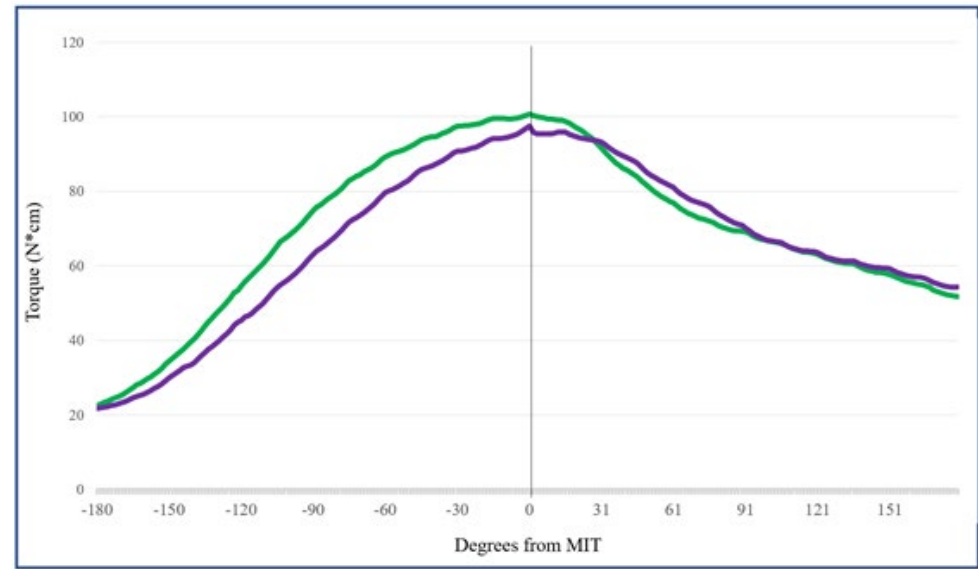

Figure 4. Insertional torque (in N-cm) measured $180^{\circ}$ before and $180^{\circ}$ after MIT reinserted screws of appropriate length (NS; purple) and for reinserted CS (green)

\section{DISCUSSION}

Based on the initial hypothesis, a decrease in MIT after CS reinsertion compared to NS reinsertion was anticipated. Since no statistically significant reduction in MIT was found, this hypothesis must be rejected. The results supported the surgeon's practice of cutting screws which are determined to be too long during osteosynthesis as a cost savings measure, as CS reinsertion did not compromise MIT in either the normal cortical bone or osteoporotic bone models. Based on these data, we believed that surgeons may reintroduce screws which were cut or shortened during fracture fixation without regard to a patient's bone quality.

The health care cost savings resulting from this practice may be substantial as long screws were present in approximately $25 \%$ of constructs. $^{14,15}$ If an orthopaedic surgeon performs 500 cases per year, then an estimated 125 cases have potential cost savings associated with cutting a screw. For nonlocking cortical screws at $\$ 20$ per screw, there could be a cost savings of $\$ 2,500$ per year. For interlock screws like those used in a tibial nail at $\$ 240$ per screw, there could be a cost savings of up to $\$ 30,000$. Thus, the financial implication of just a single surgeon adopting the practice of cutting screws would be impactful.

Although there are various parameters to quantify screw purchase, the use of MIT is most appropriate for this study. MIT has been recommended as the preferred method for quantifying compression from the screw head against a compression plate. ${ }^{8}$ This compression maintains the stability of the plate-screw construct and has been shown to be a predictor of successful internal fracture fixation. ${ }^{11,16,17}$ Lack of stability leads to problems such as screw loosening and cutout, which may require reoperation and result in poor patient outcomes. ${ }^{18-21}$ Previous biomechanical studies have demonstrated decreased screw pullout strength after screw reinsertion. ${ }^{22,23}$ However, these studies should changes in screw design affected MIT but did not correlate with pullout strength.

The findings regarding MIT with screw reinsertion were consistent with previously published studies. For example, Marmor et al. ${ }^{7}$ found that screw purchase was not affected adversely until the third reinsertion in a normal cortical bone model. In their osteoporotic cortical bone analog, the $8 \%$ decrease in MIT observed with the first reinsertion was not statistically significant. Similarly, this study did not show a significant difference in MIT with screw reinsertion, indicating that the practice of removing a screw which was too long, cutting the tip, then reinserting the CS did not weaken the construct as measured within clinically relevant ranges.

When examining insertional torque in the $180^{\circ}$ of screw head rotation leading up to and following MIT, there were no significant differences in torque between NS and CS. As MIT is reached at a single point in time (or turn of the handle), very rarely is MIT achieved in a clinical setting. One study showed that orthopaedic surgeons strip up to $20 \%$ of screws that are placed. ${ }^{24}$ Thus, it is reassuring that the insertional torque on a CS increases (and decreases) at a rate like a NS.

There were several limitations to this study. One was that the upper limit of MIT was not reached for tests with the normal cortical bone analog which precluded quantitative measure of differences in MIT in the NS and CS test conditions. Another limitation was that only stainless steel screws were studied. Titanium is more malleable than stainless steel and has different mechanical properties. Therefore, cutting a titanium screw may produce more deformation of the distal threads and lead to a different test result. Likewise, cutting screws of different sizes may have an impact on MIT. A final study limitation was that bone analogs were used instead of human cadaver bone. The results, therefore, may not be extrapolated directly to in vivo human bone.

In conclusion, this study showed that cutting a $3.5 \mathrm{~mm}$ stainless steel cortical screw did not decrease its purchase as determined by maximal insertion torque in normal cortical bone or osteoporotic cortical bone models. During osteosynthesis, orthopaedists may choose to remove screws which are too long, cut the screw tip to remove excess length, and reinsert the screw without compromising the fracture reconstruction, while at the same time avoiding implant waste and saving health care dollars.

\section{REFERENCES}

${ }^{1}$ Payne A, Slover J, Inneh I, Hutzler L, Iorio R, Bosco JA 3rd. Orthopedic implant waste: Analysis and quantification. Am J Orthop 2015; 44(12):554560. PMID: 26665242.

${ }^{2}$ Gurnea TP, Frye WP, Althausen PL. Operating room supply costs in orthopaedic trauma: Cost containment opportunities. J Orthop Trauma 2016; 30(Suppl 5):S21-S26. PMID: 27870670.

${ }^{3}$ Collinge C, Hartigan B, Lautenschlager EP. Effect of surgical errors on small fragment screw fixation. J Orthop Trauma 2006; 20(6):410-413. PMID: 16825967.

4 Patel PSD, Shepherd DET, Hukins DWL. The effect of screw insertion angle and thread type of the pullout strength of bone screws in normal and osteoporotic cancellous bone models. Med Eng Phys 2010; 32(8):822-828. PMID: 20558097.

5 Ramaswamy R, Evans S, Kosashvili Y. Holding power of variable pitch screws in osteoporotic, osteopenic and normal bone: Are all screws created equal? Injury 2010; 41(2):179-183. PMID: 19747678.

6 DeCoster TA, Heetderks DB, Downey DJ, Ferries JS, Jones W. Optimizing bone screw pullout force. J Orthop Trauma 1990; 4(2):169-174. PMID: 2358933. 
${ }^{7}$ Marmour M, Mirick G, Matityahu A. Screw stripping after repeated cortical screw insertion - Can we trust the cancellous "bailout" screw? J Orthop Trauma 2016; 30(12):682-686. PMID: 27870691.

${ }^{8}$ Ricci WM, Tornetta P 3rd, Petteys T, et al. A comparison of screw insertion torque and pullout strength. J Orthop Trauma 2010; 24(6):374-378. PMID: 20502221

${ }_{9}$ McGuire RA, St. John KR, Agnew SG. Analysis of the torque applied to bone screws by trauma surgeons. Comparisons based on years of experience and material of implant construction. Am J Orthop 1995; 24(3):254-256. PMID: 7773668.

${ }^{10}$ Cleek TM, Reynolds KJ, Hearn TC. Effect of screw torque level on cortical bone pullout strength. J Orthop Trauma 2007; 21(2):117-123. PMID: 17304067.

${ }^{11}$ Egol KA, Kubiak EN, Fulkerson E, Kummer FJ, Koval KJ. Biomechanics of locked plates and screws. J Orthop Trauma 2004; 18(8):488-493. PMID: 15475843.

12 ASTM International. ASTM F1839-08. Specification for rigid polyurethane foam for use as a standard material for testing orthopedic devices. https://www.astm.org/f1839-08r21.html. Accessed November 22, 2021.

13 ASTM International. ASTM F543-17. Standard specifications and test methods for metallic medical bone screws. https://www.astm.org/f0543-17. html. Accessed November 22, 2021.

${ }^{14}$ Cain ME, Doornberg JN, Duit R, Clarnette J, Jaarsma R, Jadav B. High incidence of screw penetration in the proximal and distal tibiofibular joints after intramedullary nailing of tibial fractures - A prospective cohort and mapping study. Injury 2018; 49(4):871-876. PMID: 29503014.

${ }^{15}$ Langerhuizen DWG, Bergsma M, Selles CA, et al. Diagnosis of dorsal screw penetration after volar plating of a distal radius fracture. Bone Joint J 2020; 102-B(7):874-880. PMID: 32600133.

${ }^{16}$ Perren SM. Physical and biological aspects of fracture healing with special reference to internal fixation. Clin Orthop Relat Res 1979; 138:175-196. PMID: 376198.

17 Edwards TR, Tevelen G, English H, Crawford R. Stripping torque as a predictor of successful internal fracture fixation. ANZ J Surg 2005; 75(12):1096-1099. PMID: 16398818.

${ }_{18}$ Ricci WM, Tornetta P 3rd, Borrelli J Jr. Lag screw fixation of medial malleolar fractures: A biomechanical, radiographic, and clinical comparison of unicortical partially threaded lag screws and bicortical fully threaded lag screws. J Orthop Trauma 2012; 26(10):602-606. PMID: 22437423.

${ }_{19}$ Claessen FMAP, Braun Y, Peters RM, Kolovick GP, Ring D. Plate and screw fixation of bicolumnar distal humerus fractures: Factors associated with loosening or breakage of implants or nonunion. J Hand Surg Am 2015; 40(10):2045-2051.e2. PMID: 26319772.

${ }^{20} \mathrm{Kim}$ JW, Oh CW, Oh JK, et al. The incidence of and factors affecting iliosacral screw loosening in pelvic ring injury. Arch Orthop Trauma Surg 2016; 136(7):921-927. PMID: 27168134.

${ }^{21}$ Meeuwis MA, Ter Gunne AFP, Verhofstad MHJ, van der Heijden FHWM. Construct failure after open reduction and plate fixation of displaced midshaft clavicular fractures. Injury 2017; 48(3):715-719. PMID: 28129880.

${ }^{22}$ Matityahu A, Hurschler C, Badenhop M, et al. Reduction of pullout strength caused by reinsertion of $3.5 \mathrm{~mm}$ cortical screws. J Orthop Trauma 2013; 27(3):170-176. PMID: 22534691.

${ }^{23}$ Mejia A, Solitro G, Gonzalez E, Parekh A, Gonzalez M, Amirouche F. Pullout strength after multiple reinsertions in radial bone fixation. Hand 2020; 15(3):393-398. PMID: 30188185.

${ }^{24}$ Gustafson PA, Geeslin AG, Prior DM, Chess JL. Effect of real-time feedback on screw placement into synthetic cancellous bone. J Orthop Trauma 2016; 30(8):e279-284. PMID: 26978139.

Keywords: biomechanics, fracture fixation, medical waste, bone screws, torque
KANSAS JOURNAL of MEDICINE CUT CORTICAL SCREW PURCHASE continued. 